\title{
Preliminaries to the Study of Morality and Law ${ }^{1}$
}

\section{Universal Benevolence}

However, secondly, an individual may behave socially by feeling universal benevolence. It is by no means true that an individual is always driven by their own interest and always and only strives for what brings them a personal gain. Human nature can be driven by disinterested pursuits that are aimed towards something that is neither one's own pleasure nor a lessening of one's own distress. An individual often pursues something that does not bring them any personal gain and that they must pay for with considerable or even great distress: they work for others, renounce their own joys, risk their life to promote the welfare of others or to spare them from suffering. Admittedly, having achieved their unselfish aim, the individual often feels very great joy; but the joy is only secondary and it is not because of it that they continue their pursuit that has somebody else's welfare in view. The joy is a shadow, as it were, that follows an outgoing pursuit.

There are various outgoing pursuits. A mother's love strives to provide her child a maximum of joy and pleasure, and spare the child as much suffering as possible; in other words, she strives to maximise the

1 Translated from: C. Znamierowski, Rozważania wstępne do nauki o moralności i prawie, Warszawa 1966 by Tomasz Żebrowski and proofread by Stephen Dersley and Ryszard Reisner. The translation and proofreading were financed by the Ministry of Science and Higher Education under 848/2/P-DUN/2018. 
child's happiness or, to put it differently, to ensure the child receives the greatest share of happiness possible. The same pursuit is shown by sexual love; the same, but perhaps not so strong, by friendship and that kind of goodwill that is distressed to see others suffer and rejoices in somebody else's joy. This goodwill is colloquially called benevolence. It is more or less active, depending on how ready it is to contribute to the happiness of the person to whom it faces.

Benevolence may be directed at a specific individual: it is individual then. Moreover, Peter may show benevolence to many people, to every person individually, when they find themselves in need of protection or help. In an extreme case, the individual's heart may be so sensitive as to make them show benevolence to all who get into trouble or are harmed. Then their benevolence will be general, because it will be shown to every person individually and separately.

Such general benevolence is clearly distinguishable from consciously universal benevolence. It is absolutely aware of the fact that it turns towards every individual, values the existence of all people equally, desires the greatest share of happiness for each of them and, finally that it is ready to support and make this desire come true through its own action and effort. What is more, when the benevolence gains some life experience, it will know that the happiness of some entails positively or negatively the happiness of others: the happiness of a mother follows largely from the successes of her child, while the happiness of one contestant is limited by the success of another. Hence, in the mind of universally benevolent Peter, all people become one mass of whom he thinks and must think jointly when he pursues the maximum happiness of all people: due to this, he may not go too far in their desire of happiness for individuals considered severally, and thanks to this, universal benevolence has an inherent restraining factor that emotions and pursuits usually lack. Moreover, benevolence may turn consciously and intentionally not only towards every individual, but also towards every living creature capable of rejoicing and suffering. 
In a primitive closed community, benevolence extends to every fellow tribesman; in a nation, where bonds can be clearly seen, it covers every compatriot; at the highest level of spiritual development, it turns towards every individual and is universal in the strict sense of the word and thus it transcends the boundaries of any and all closed communities. Its way has been paved by free thought, which indicated that one individual resembles another and that everyone rejoices and suffers in the same way. This simple idea has effectively and gradually brought down the wall of megalomania within which various nations enclosed their communities. It must be added that benevolence is truly universal only when it is fully conscious that its object is every individual, wherever on earth they live.

Universal benevolence is the most certain and reliable foundation of socialisation; whoever feels it will most likely show consideration for others, sympathise with and offer help to them. Therefore, we put the greatest confidence in the people of whom we know that they feel universal benevolence that is vigilant and strong. It is such people that we call good, which means that they love their neighbours; actually, universal benevolence and love of one's neighbour are one and the same thing.

Admittedly, many writers think that someone who judiciously takes care of their business reckons equally well with others' business, as a good person does. In other words, they say that judicious personal calculation produces the same guidance as universal benevolence; what is more, that the judicious love of one's own self brings the same share of happiness as love of one's neighbour. This last-mentioned thesis though, is a risky generalisation that cannot possibly be sufficiently confirmed; nor can one claim that love for one's 'self' is always judicious. Therefore, it is reasonable that good people enjoy greater confidence than judicious egoists do; and that almost everybody at least wants to be regarded as good by others, if only to dull their vigilance. Everybody knows that sharp claws are a great gift of nature if they can be hidden in soft paws. That is why, since time immemorial hypocrisy has been paying due tribute to universal benevolence. 
This benevolence, in turn, is a natural umpire, a superordinate arbitrator, in communal life. Other pursuits and emotions often vary greatly from person to person. Love of one's own "self” in one person often entails that they deliberately wish harm to another person. One person's ambition strives towards the exact opposite objective than that of another person. By the same token, one person's greed easily runs afoul of the greed of another.

A quite different story is that of universal benevolence in various people: it pursues the same objective in all, namely, to maximise everybody's share of happiness. Thereby universal benevolence develops a natural bond between people, that is, a unity of purpose. This emotion does not divide; it rather unites people and easily draws an emotional response from others that increases and amplifies benevolence. That is why disapproval by universal benevolence is so grave a judgement in communal life, for it is always highly probable that it will spread in the community. Thus, although universal benevolence is an emotion, generally speaking, of moderate strength, the social response amplifies it greatly and awakens it anew in various situations, making it vigilant and providing it with a great penetrating force: only rarely does it explode in violent outrage, it rather makes itself felt through a reproach that nags stubbornly like a minor but unbearable pain.

Universal benevolence, it is true, may sometimes apparently divide people in an extreme case, where Peter and John do not agree on the means to the same end. Such a conflict, however, is not a deep rift, because there are no pursuits here that cannot be reconciled. It is easy to agree on means when people are bound by the same emotion, especially universal benevolence. It is enough to have the same knowledge on the laws of nature.

\section{Moral Judgement}

Universal benevolence is interested only in people or, at best, those living creatures whose fate elicits a strong emotional response from 
humans. It is pleased with all that reduces human suffering or brings people joy. This is judged by it as positively valuable. It is displeased by all that brings or increases suffering or reduces or destroys joy. This is judged by it as negatively valuable. In the eyes of universal benevolence, various things may be positively or negatively valuable; positively valuable things are, for instance, a medication which radically contains an epidemic, a highway that makes travel easy for everybody, a forest that offers beautiful views and supplies timber for furniture and heating homes; negatively valuable things are, on the other hand, a drought that destroys crops or a flood that washes houses away.

However, universal benevolence focuses in particular on the attitude of the individual towards others. For it is in a community that the life of every individual is lived; their joys and suffering largely depend on the conduct of others. For this reason, universal benevolence scrutinises what emotions an individual feels towards their neighbours, what secret pursuits are hidden in such emotions and what actions and pursuits result from such emotions that have a positive or negative impact on the share of happiness of other people.

The judgement passed by universal benevolence, whose object is an emotion felt by one person for another, a pursuit concerning another or an action that influences the fate of another or other persons- this judgement is known as a moral judgement. At the same time, the only generator of moral judgements is universal benevolence: this makes such judgements stand out sharply and distinctly from others. Emotions, pursuits and actions concerning other people may be also triggered by other emotions than universal benevolence; these other emotions may also generate judgements, not moral ones though - judgements of some other kind. Let's say Peter likes the courage with which John defends Adam against danger. Peter, therefore, positively judges John's conduct: the judgement in this case is aesthetical and not moral. Here again Eve is angry with John, because he has punished her son; she bears a grudge against him: the generator of the judgement is ma- 
ternal love; this judgement is not a moral one either. The same emotion or action, however, may be the object of two or more emotional reactions at the same time and in the same individual. Peter's universal benevolence may morally approve of the courageous way that John helped Adam and, at the same time, Peter may like that courage.

The closest object of moral judgement for every individual is their own experiences and actions. An individual may judge them right after they happen, when they are still fresh in their mind or later when they have already moved into the past from which memory brings them back. In addition, every person, as a rule, can judge more deeply and justly their own experiences, because they can, if they so wish, probe them more deeply and notice what is completely inaccessible to others. Universal benevolence as a generator of moral judgements, which concern one's own experiences and actions, is called conscience. As mentioned earlier, universal benevolence provokes rather moderate emotional reactions, or even weak ones, but often they are persistently recurrent: this is the source of their strength and role in consciousness.

Universal benevolence places a positive value on emotions and actions that are favourable or friendly to other people. In turn, it assigns a negative value to the emotions and actions that are unfavourable or unfriendly. A sound conscience, however, one not selfishly directed at one's own self and person, does not pay equal attention to its emotions and actions, either morally positive or negative. Universal benevolence above all intends to prevent other people from being harmed; hence, it is quick to nip in the bud even those experiences and predispositions to experiences that may beget injurious actions. Moreover, it scrutinises actions that have already caused harm, but gives less attention to the emotions and actions that are friendly to people. Hence, conscience very rarely praises but frequently reprimands, because under its inquisitive eyes there is a lot of wickedness in a human soul when viewed from the inside. 


\section{Social Moral Judgement}

When Peter's universal benevolence judges his own experiences and actions, it is his own internal concern, touching his person, and may not be known to anybody else: thus, it is an individual judgement. Peter's benevolence though, may also be interested in the experiences and actions of other people, because they may be highly relevant for those whom they concern. Peter may be really worried by John's hatred for Adam as it may beget an action harming Adam. Stemming from universal benevolence, Peter's judgement of John's experience or actions directed at Adam, is a social moral judgement.

In the judgement, three persons are involved: Peter who judges, John whose experience or action is being judged and, finally, Adam whom John's experience or actions concern. This may be presented in a schematic manner as follows: A in their universal benevolence judges an experience or action of person B directed at person C. Moreover, it is possible that the experience or action concerns not just one person C, but many people or an entire group: thus B hates Egyptians or the monarchy of Ramses XII.

In this case, too, universal benevolence is a generator; but it keeps an uneven eye on persons B and C; specifically, it preferentially turns towards $\mathrm{C}$ and person $\mathrm{B}$ is subordinated to the interests of $\mathrm{C}$, because the experience or action of $\mathrm{B}$ is judged in terms of the welfare of C. Especially when A negatively judges the experience or action of $\mathrm{B}$, it may appear that A, contrary to universal benevolence, has an unfavourable attitude towards B, while A's attitude towards C is biased and preferential. Actually, however, A remains benevolent in respect of B as well; they only demand of him what universal benevolence lets him demand or rather tells him to demand. What is more, if John and Adam traded places in the triad, Peter would subordinate Adam to John, or C to B in the same manner. In fact, people do this all the time in real life, alternating between judging the experiences and actions of one or the other. 
When Peter judges his own experience or action, he splits, so to speak, into two persons, A and B. Since, however, the judgement concerns his own experience, it quite naturally enjoys a considerable causative power in Peter's soul and produces an impulse that amplifies the force of the experience further or weakens and restrains it, depending on whether it is positive or negative. The moral judgement, thus, of one's own experience or action always has a smaller or greater impact on Peters experiences and attitude.

However, Peter's judgement concerning John's experience does not have to have any causative power in the soul of the latter. In an extreme case, John may not care at all what Peter thinks about his experience or emotion, and he may not care about Peter as a person either. It may not matter at all, either, that Peter's judgement was engendered by universal benevolence, since John may not know this emotion and does not heed its suggestions. Then, Peter's judgement does not elicit any emotional response in John's soul.

John himself though, may feel universal benevolence to some degree. As the voice of conscience, it could have already passed judgement on a given emotion or action before John learned of Peter's judgement. If it is consistent with his, it will elicit a positive emotional response and amplify it considerably. If there are many-or very many-such Peters who judge a given experience in the same way as John does, the consistency takes away relativisation from the moral judgement in his eyes: it appears to John that his own judgement and the judgements of Peters who agree with him do not depend on their experiences, but they rather appear and suggest themselves to them in the manner in which descriptive truths do, irrespective of any emotions and pursuits. This is a common and almost unavoidable illusion whereby in a group we stop noticing or simply do not notice the factors that make up the sufficient cause of that factor which is invariably given in the group. It is only natural that John forgets that it is universal benevolence that tells him and all his Peters to pass the same judgement, and that it appears to 
him that he finds and notices the values of experiences and actions in the same way as he does the shapes and colours of objects. Nonetheless, there are no absolute values; there are only values here invariably stemming from some emotion that is common among given people.

Hence, when a judgement is expressed in words, it is always necessary to indicate what emotion or pursuit it stems from. To indicate, thus, that a given judgement is moral, it must be mentioned that it stems from universal benevolence. This emotion, roughly speaking, always and in every person dictates the same judgement; in principle, therefore, it is not necessary to indicate each time in whose soul universal benevolence forms a given judgement. It often happens, though, that a global judgement of some object or event depends largely on Peter's knowledge of the laws of nature and the entire set of factors that come into play in a given case. It is desirable then to indicate the person who forms the judgement, because in this way one implicitly indicates what knowledge of the object the person has when making the judgement in question.

A consistent judgement by many Peters may have a persuasive power over John even when he does not spontaneously formulate a moral judgement of his experience or action. It is quite probable that John either has, albeit deeply hidden, a predisposition to be moved by universal benevolence or at least, he may imagine the attitude taken by this emotion by analogy to his other emotions. He himself feels at least equal benevolence towards his family members or friends. He may thus imagine how he would judge somebody else's experience or action if he extended his benevolence to all people. In the first case, a universal judgement will uncover their own universal benevolence and stir their conscience; in the second case, the judgement will at least tell him how to behave so as not to incur universal disapproval. Further, if he continues to heed this guidance and behave as if he were guided by universal benevolence, it is likely that he will learn to look with the eyes of universal benevolence, either because this emotion, hitherto unknown to him, will rise in him, 
or because he will develop a habit of action consistent with the directions of this emotion.

An important aspect for communal life is the fact that John may adopt ready-made judgements from his Peter or Peters. Imagine that because of a lack of experience or any relevant knowledge, John is not suggested any judgement by universal benevolence in a given case. John though, learns that Peter, whose universal benevolence is tested, judges a thing in a specific manner. If John generally believes that Peter's moral judgements are right, his judgement will easily elicit a response from John's soul and will become his judgement, one of credit, so to speak, based on the belief in the rightness of Peter's judgements. It often happens that Peter praises the moral value of Adam's deed, who has brought about many momentous changes in communal life. John is not able to judge these changes by himself, but eagerly adopts Peter's judgement, deeply moved by admiration or outrage or contempt. Furthermore, John may continue to uphold this induced judgement, although Peter may later modify his.

The Peter who suggests a judgement may be not just a person, but also a being of a higher order than a person-a being in whose existence and goodness John believes. In the lively imagination of the ancient Greeks, gods told them, often in detail, what was right and wrong. Whereas Christianity makes God the principal source of fundamental moral precepts and makes divine judgements a model and touchstone. This religious belief lends much support to the suggestive power of moral judgements: they may not give rise to any doubt, because they come from an absolutely perfect Supreme Being who is an embodiment of universal benevolence.

\section{The Object of a Moral Judgement}

As already said, universal benevolence scrutinises emotions, pursuits and actions that are directed at other people. These experiences and ac- 
tions, however, are treated by universal benevolence in two ways, depending on how they are treated by the person who undergoes or performs them.

Emotions and pursuits arise in consciousness spontaneously, without permission. In the eyes of conscience, they are valuable either positively or negatively. Those that are favourable or friendly to people are generally judged positively, while unfavourable or unfriendly-negatively. It is good when an individual feels sympathy, benevolence, gratitude and respect for other people; it is bad when they feel envy, anger and hatred. Even emotions and pursuits favourable to people though, may come into conflict. To name two examples, love for a wife may sometimes stand in the way of the love of a child. Love for a villain may morally infect the whole nation. In the eyes of universal benevolence only universal benevolence is the emotion that is always valued positively, because it always has in view the welfare of all people, not only some selected ones as other emotions favourable to people do. The latter may want too great a share of happiness for their chosen ones.

The spontaneous appearance of an emotion or pursuit in John's soul does not depend on John's will but on the entire structure of body and soul on which he had little influence, or none at all. Nevertheless, already here Peter judges these experiences and, possibly, from judging them he goes to the judgement of the whole person of John if these experiences can be seen to have been borne out of a deep and lasting predisposition. Peter judges then that John is good by nature if predispositions favourable to people predominate in him, especially universal benevolence; whereas Peter judges him to be bad by nature if predispositions unfavourable to people predominate in him.

Even though an individual receives a considerable legacy of readymade emotional predispositions, they have, after all, some power over their emotions and pursuits. As we shall soon see, they can by acts of will allow or not allow for the experiences that have already arisen, or prevent them from arising. Anger at Adam may arise spontaneously in 
John's soul, but John may allow it to burst out, or he may oppose and contain it so that it will subside and disappear without doing any harm to Adam. In the latter case, Peter, while judging Adam, will consider as less important the appearance of anger as such since universal benevolence will effectively control it. Furthermore, John may, knowing himself, fend off the thoughts that arouse anger at Adam in time to prevent one of the most unfriendly emotions from arising.

This power over one's experiences is enjoyed, to some degree and within certain limits, by every normal individual: they interrupt the course of thoughts that leads to an undesirable emotion or pursuit, or restrain or weaken the undesirable experience by directing their thoughts at something else or changing their situation so that it disappears by itself or is replaced by another experience that will cover and eclipse it. If John does not make these efforts to oppose his experience and allows it-being negatively valued by Peter-it will grow even more negative, as the one that John has allowed and consciously made as one of his experiences. Universal benevolence scrutinises these experiences that our will has allowed by giving them a privileged position in our consciousness, the reason being the fact that these experiences may spawn actions, the effects of which will encroach on the ambit of other people's existence.

Actions, in turn, are an especially important object of a moral judgement, because in the eyes of universal benevolence what counts most is stopping one individual from harming others by their action and making them contribute the most to their happiness. A hidden and contained emotion does not have a chance yet to harm anybody or make them happy. It may harm or make happy by the very fact of its divulgence; the more so when it is realised in an unfriendly or friendly action.

We have split the person of Peter in two by carving John out of him so as to make clear that Peter may morally judge not only his experiences and actions, but also somebody else's. It must be remembered, however, that a moral judgement is above all the inner voice of conscience that looks into experiences directly, not having to pierce the armour of 
another person's mortal coil, and that it judges not actions alone, which can be viewed from without, but the very motives of these actions within that grow out of unseen experiences.

The insight into one's inner life may sometimes be misleading, however, because every individual tries to show themselves in the best possible light, even to themselves. Unwittingly, they find ways to hold back from their own self, in the inner split that is created in the soul when conscience sits in judgement, amidst the stirrings of emotions and motives of action that would cast a negative light on their person or their action. Considerable moral discipline is needed, as well as inner honesty and correct insight into one's emotional experiences, to summon the available courage to bring to light the inner experiences that lower one's self-esteem. Individuals shield themselves from this with hypocrisy, which even creates an inner show of semblance and illusion to hide the foul stench of their moral entrails.

Peter's universal benevolence is not able to look into somebody else's experiences with certainty and perspicacity. Every John screens his spiritual sanctum from the piercing eyes of others, and even when he himself has a clear and undistorted view of his inner life, he tries to draw a cobweb of falsely favourable appearances over it. Peter, therefore, as a judging spectator, can only carefully watch observable behaviour and draw cautious conclusions. He can never determine the measure of their probability with accuracy. The average Peter tends to be insufficiently cautious in his presumptions regarding other people. When he is cautious enough, he must necessarily place his moral judgements of others on two levels. On one level, there are judgements that are moral in the strict sense, where Peter believes himself to be looking into somebody else's inner life and almost sees the stirrings of John's emotions and the motives of his actions. On the other, there are judgements of actions themselves and their socially relevant effects.

These judgements will not be moral in a strict sense; they will pass judgment only if an action by John has conformed to the guidance that 
would be given by universal benevolence in a given case. This does not rule out that the action was born out of cold selfish calculation, which would deprive it of any moral value. In everyday life, we usually do not notice the difference between these two kinds of judgement and do not appreciate its weight. An individual who always behaves like a good individual seems to be good to us, although in reality they might be only calculating, cautious and cunning. Again, people are ashamed to show their goodness and even conceal the soft and sensitive stirrings of their hearts, thus they make their good deeds look like the business-like performance of an external duty. In addition, sometimes it takes special circumstances, those breaking the daily routine, for a cold calculation or a downright undesirable moral emotion to come out from behind an action overtly consistent with a moral norm. Although it is usually not conceived out of universal benevolence, the stinging wit of a satirist is aimed at prudes and hypocrites.

However, in terms of social needs, the second, less demanding kind of judgement is sufficient for communal life. It is by no means a bad thing when people follow moral norms in their conduct, even if when they do so they are not guided by moral motives.

\section{The Principal Moral Norm}

Universal benevolence, as was mentioned earlier, strives to ensure an equal share of happiness to all people. Thus, it believes that it would be good only when the general conditions in which people live were such that all would have an equal chance to get a maximum of pleasure with a minimum of suffering. Living conditions depend largely on the environment and human action cannot influence them. However, they depend not in small part on how people treat one another and what they do for one another. Importantly, the larger the number of powerful tools people have at their disposal, the greater the impact their action has on their happiness. Thus it is only natural that universal benevolence would like every 
individual to meet all the conditions necessary for making the greatest contribution to the enlargement of the share of happiness of all people. Hence, it is natural that universally benevolent Peter values universal benevolence most in people, as it is the only emotion that is focused on all people and wants happiness for them.

Universal benevolence concludes, therefore, that the human world would be good only if all people were universally benevolent. Hence, it believes that every individual should be universally benevolent and that this benevolence should effectively guide them in every action. Hence, the only principal norm that universal benevolence sets is the precept that every individual should be universally benevolent and should be guided by this benevolence in every act of their will, as either a positive impulse to act or an impulse restraining other actions.

This norm tacitly assumes that every individual has at least the germ of this emotion, which they may develop fully and make an important component of their constellation of emotions. This assumption is not fully justified, as there certainly are people who are unlikely to ever allow universal benevolence to develop in their soul. These are extreme cases, however; people who are completely lacking in this emotion whatsoever are considered abnormal and morally underdeveloped. They are unable to give moral judgements or even imagine them by an emotional response, since they lack this predisposition that by response could be actualised in an experience.

However, in spiritually normal people, benevolence a universal feeling, sometimes only embryonic or weak, sometimes strong, pervading the entire constellation of emotions. The principal moral norm makes it an individual's obligation to give benevolence a decisive say in their decisions.

By a deliberate effort of will, this emotion may be given a dominant position. All that is needed is to form a habit of imagining the joys and suffering of other people. The habit usually gives rise to, and increases the capacity for, an emotional response to somebody else's joys and 
suffering. Will, therefore, may affect this emotion to an extent. In that case, it may be an individual's obligation to develop and strengthen this emotion in themselves.

Since, however, every individual ought to be universally benevolent, universal benevolence should ipso facto extend its control to their entire behaviour. The principal moral norm then takes on another form that clearly and in detail sets out what a universally benevolent individual should do and what they should refrain from doing. It says now: "every individual should as best as they can": first, "refrain from any action that contributes to somebody's suffering, second, actively reduce the sum of suffering of other people" third "refrain from any action that kills other people's joys" and fourth, "actively increase the sum of contentment of all people”.

The principal moral norm has split into four component norms that are independent from one another. The first two concern the person's attitude in the face of human suffering, while the second two-somebody else's joy. The first and third prescribe omission while the second and fourth-an active attitude.

For human happiness, all four prescriptions are important, because to achieve it a person needs a maximum of joy and a minimum of suffering. Indeed, universal benevolence, in its desire for happiness for all people, in principle, puts the four obligations on an equal footing. However, to direct human conduct really effectively, universal benevolence must realistically judge what can be effectively demanded of people. It cannot demand too much and must reckon with what response somebody else's joy and suffering usually draws from a given individual.

Actually, even the most universally benevolent Peter is unequally vigilant and sensitive to the pleasant and unpleasant experiences of other people. His eye and attention are caught first of all by the suffering of other people, and he strives above all to prevent the suffering of others and remove that which has already arisen. He will be morally shocked and outraged when he sees John deliberately contribute 
to Adam's suffering. He will also think badly of him when he sees that John is indifferent to Adam's suffering and that he does not offer him any help. He will not be so shocked and outraged, however, when John stays indifferent to the joy that Adam experienced: he can be left alone when he is joyful. However, in this case too, Peter will be worried by John's moral attitude if he sees that he is in the habit of not responding emotionally to the joyful experiences of other people. He will think then that John's sources of universal benevolence are limited after all, and that he cannot be counted on to take some action to give others joy. John's benevolence will appear cold and incomplete to him, although he will not deny him any moral value for this reason, provided that John is sufficiently vigilant and sensitive to other people's suffering.

Reckoning realistically with the diverse nature of various people, Peter will cautiously create a gradation of moral requirements. He will judge that John is not bad if he does not deliberately do any harm to anybody, in particular, if does not even have an impulse to harm somebody: you do not have to be on your guard against a John like this. In this case, he respects the first of the mentioned norms that establishes a minimum of moral requirements. The individual who breaches this norm and deliberately adds to the suffering of others acts already in a morally wrong way.

Higher moral requirements are set in the second norm that prescribes an active contribution to the alleviation of other people's suffering. John does not show universal benevolence, at least not actively, if he does not offer help when he sees Adam's suffering. Even if this suffering has elicited some response from John's soul, it attested to only a flicker of universal benevolence in his soul, obviously not strong or lively enough to make him act; it is like a seed incapable of germinating. Hence, an individual is not actively good if they do not live by this second norm; externally, they do not differ much from one who is simply not bad. In contrast, a person is visibly good if they are effectively stimulated by benevolence to give help in suffering. 
The next place in the gradation of moral requirements is occupied by the third norm. It can be said that it, too, extends and supplements the moral minimum whose foundation is the first norm. It is clearly wrong for John to remove Adam's source of joy or deprive him of it, even though he has not caused Adam to have a painful experience, due to his regretting that an awaited joy has not come. For instance, John is wrong to block Adam's beautiful view with a high wall, or to withhold news from him that would make him very glad. For taking somebody's joy away means limiting and reducing their share of happiness. With this kind of behaviour, the bad intention does not differ much from that characterising an action that causes deliberate suffering.

However, universal benevolence is fully embodied only in the fourth norm that prescribes the active multiplication of other people's joy, which involves effort. They who do this prove beyond doubt they care a lot about the happiness of other people, elevating to the highest level of universal benevolence. Only by doing good to others with the aim of increasing thereby the sum of happiness of all people does an individual become really good.

\section{Comments on the Principal Norm}

At a first glance, these four norms that extend the concise principal norm seem to place too great a burden on an individual. It is still relatively easy to take care not to add to other people's suffering by direct action - that is, not to inflict injuries or cause immediately visible damage. However, it is very difficult to anticipate accurately and for a more distant future if indirect effects and distant actions may unexpectedly become detrimental to one individual or even many. Even if a person knows very many laws of nature, the most perspicacious mind is not able to make accurate forecasts for the distant future, especially ones concerning the communal life of great groups of people. Similarly, it is very hard to predict if somebody will not be deprived of a dose of happiness by some incautious, albeit 
good, action. If John latches a door through everyday habit, he will spoil Adam's bicycle ride as he will be unable to fetch his bicycle from the flat. So to avoid harming somebody and detracting from their pleasure, an individual must be constantly vigilant and make use of their entire knowledge of the world to avoid harming others.

A still greater effort is necessary-greater because active- to give help to every person who cannot cope with the burdens of life without it. There are too many people in need of such help in the world. To ask an individual to give help to all is to ask too much. The question thus arises of how far the obligation to provide help extends. In addition, marking the limits of the obligation, an individual may easily, as it seems, narrow their universal benevolence to some restricted community, against the prescription of the principal norm.

Finally, the fourth norm imposes such a great burden that is seems to be unrealistic. How can individuals, who are always so restricted in what they can do, actively multiply the happiness of all humanity? They do not have enough knowledge or power for that, so that cannot truly be their obligation. Therefore, the prescriptions of these norms must be made more specific so that they do not become hollow desires.

First and foremost, it must be realised that moral norms concerning actions extend only as far as the power to act of a given individual extends. Moreover, this power is very limited. First, the knowledge of an individual and their power of prediction, necessary for any rational activity, are very limited, especially when an activity affecting large communities is involved. The knowledge of the broadest and most perspicacious mind is so limited that it is incapable of predicting the diverse plurality of effects that every action generates. An unguarded remark may sometimes weigh heavily on the life of an individual or their entire circle. An unwary signature of a statesman may bring misery to a whole nation. However, to reach with our mind into the future so as to be able to see clearly the entire growing sequence of effects is not possible. 
Second, the power of action, the bodily and mental energy necessary to make bodily movements and mental efforts, indispensible for any action, is very limited in human beings. Even the best individual cannot watch over a bedridden person day and night; even the most self-sacrificing person will not feed a million of the hungry alone, because they will tire out and run out of the food that they would be able to distribute. It is these physical aspects, which are the necessary material and means of action, that often greatly limit the possibility of action. These limits shall be called the human range of power.

The range of power varies from individual to individual; it depends on their start in life, including the conditions for their bodily and spiritual development, and the range of things that may be its material. Sometimes the power is so limited that even with the greatest inner goodness an individual is practically unable to affect, especially positively, the fate of others. Given the structure of the community in which they live, they can barely survive on hard work, which consumes all their energy. This individual can only refrain from harming others. At the other extreme, an individual may, by means of a decision, release ever greater forces of nature or human energy, which are invisibly accumulated in organised groups. Here, again, they are short of the knowledge necessary to be able to produce only intended effects by their action and to make predictions concerning them, looking as far into the future as their range of power extends. Examples include an inventor who builds machines of great power or a statesman who, with a single stroke of his pen, sets in motion millions of people who begin fighting for their freedom.

What specific obligations are imposed on an individual by the principal moral norm depends on their range of power. Impossibilium nulla oligatio; there is no obligation to do impossible things. Hence, the weak and the powerless should respect only the first and third norm unconditionally: not to add deliberately to other people's suffering and not to deprive them intentionally of their joys. Besides, however narrow the range of their choice is, they should take care that their actions enlarge 
the global sum of human good as much as possible. The most powerful and mighty, however, who can still affect and do affect the fate of numerous people are burdened with great obligations, as they should be concerned with the level of human misery on a world scale.

Even the most powerful, however, cannot be obliged to extend their thoughts and actions to every human being individually. They can care for the happiness of human masses only in a general way, using the organisational structure of human communities as a tool. The communities, being united in one way or another, can be acted on as entities, thus indirectly and secondarily lowering or raising the share of happiness of individuals. Imagine a minister of finance ordering the salaries of officials to be raised: he/she does not know personally even the smallest portion of those whose remunerations will rise. Imagine, a great lawmaker reforming the government system of a country to improve governance: he/she does not know at all that great mass of citizens who one way or another will benefit from the reform.

The reformer still does not satisfy the obligation imposed on them by the fourth of the four norms, because their benevolent intention encompasses, admittedly, all the citizens of their country but does not encompass all people. This reformer, too, however may be driven by a universally benevolent thought: I do my best for the universal welfare of all people, namely, I improve the fate of those whom I can affect by my action. I would do the same for others if I had the power. This thought and intention can drive not only a powerful statesman, but also the smallest element of the human multitude: this thought and intention, in some humble and timid, in others proud or even haughty, give the sense of participation in the great collective work of all people of good will. To participate in this enterprise, no consent from anybody is necessary. It is in this intention as well, even if it concerns a very minor action, that the fourth norm prescribed by universal benevolence is already satisfied. It also hides a superordinate thought about not making a given action detract from the general sum of happiness; hence, the first and third norms are satisfied as well. 
However, it must be said and emphasised at this juncture that the principal moral norm does not demand at all that any human action be driven by a thought about universal happiness or that every action follow from universal benevolence. There are many actions that belong solely to the personal domain of a given individual and whose effects do not go outside this domain in any observable manner. It is marked and approved by universal benevolence itself. Hence, it is John's absolutely personal matter if he spends the time off he deserves, in the eyes of universal benevolence, taking a walk or playing chess. What is more, he does not have to walk or play chess having in mind the global sum of happiness of all humanity or perform these actions at the behest of universal benevolence. This emotion by no means dictates all actions, but only exercises general supervision over all impulses and actions in accordance with its fourfold norm.

If according to John's understanding and knowledge, tea and coffee are equally harmless to him, universal benevolence does not provide any guidance in this case. If, however, John knows that coffee is very harmful to him and may shorten his life, which is precious to his small children, universal benevolence exercises its supervisory veto. Under its eyes, John should care about the welfare of his children. It interferes in every human matter only as much as the matter, through its causal ties, comes into conflict with the interests of other people. Luckily for human freedom, there are many things in the world that are mutually independent of each other. The ripples made by a stone thrown at one shore of a lake will not reach the opposite shore. The fact of John sneezing in his room in Poznań will not have any consequences in Warszawa.

\section{The Severity of the Principal Norm}

Upon closer scrutiny, it thus appears that the principal moral norm does not impose unrealistic requirements. Nonetheless, its demands are quite stringent, as it requires that all impulses and drives, even the strongest 
and most spontaneous, be subjected to its supervision. Furthermore, it demands that an individual should always actively care for somebody else's interest and suffering and take every possible effort to maximise the overall sum of happiness. In the light of these requirements, there is not a single individual that would be morally perfect, i.e. an individual that would scrupulously and without any exception discharge all the duties imposed on them by the fourfold principal norm. Every person actually driven by universal benevolence feels their moral imperfection. The more vigorous their universal benevolence, the stronger this imperfection is felt, and the more insistently it demands respect for its prescriptions. For they see clearly that they are incapable of the vigilance and dedication that universal benevolence demands of them and that, what is worse, they resort to various tricks to cheat themselves so as to be able to forget conveniently about their moral obligations. Sometimes, facing a moral dilemma, they have to tell themselves that they do not know where the line between their right and their obligation is.

Obligations related to earning a living meet with the approval of universal benevolence, which prescribes that everybody should work in order not to be a burden on others. Earning a living consumes a huge portion of an individual's energy and makes rest necessary, to which an individual is morally entitled. Imagine that John wants to sit comfortably to continue reading a novel he has started, because he has an absolute right to do this, when he remembers at this very moment that his neighbour Adam, an old and sick man, does not have anybody who could help him with an urgent grain harvest. John realises that if he does not help Adam, his neighbour will suffer a huge loss. His universal benevolence keeps nagging him: a sense of obligation has arisen in him that somehow does not respect his right to rest. If this universal benevolence is insistent enough, the new sense of obligation will prevail over the apparently unshakeable sense of the right to rest: John will continue to expend energy working on his neighbour's field instead of recuperating it. 
Universal benevolence cannot always tell John how far he should go in helping his neighbour, or more generally, with the resignation from his right. Why, it is possible that the help for others, using up his energy, will lower his capacity for work, which is his set and unquestioned moral duty. This will be clearly seen when his neighbourhood attracts many such Adams in need of help. The problem will become acute, to the extent that so many hungry people would turn up around him that in order to feed them, if only to stave off their hunger, John would have to starve to death himself. At this point, universal benevolence will find itself in an extreme, really tragic dilemma: it will have to answer the question of whether one can morally save one's life when others perish; or, further, is it a moral obligation to lay down one's life for others to live - or even to live happily?

This is the eternal question of heroism. For those are heroes who, sacrificing their moral rights, go far beyond the average demanded by universal benevolence. It sets people obligations in moderation so that their satisfaction does not overtax the average ability of a human being. If, thus, such a directive of moderation is adopted in setting obligations, a heroic act will not be an object of a moral obligation, but a generous and particularly valuable extra: evidence that an individual gave clear priority to loving their neighbours over loving their own self. Generally, universal benevolence gives credit to John if he makes a greater effort and exposes himself to a greater loss of happiness than a moral norm tells him to.

Since, however, people on average are not very prone to heroism and do not care much about moral credit, they do good to others only out of the surplus and leeway left to them after the love of self, possibly extended to the next of kin. As a rule, the surplus is rather small in particular in societies with few material resources, in which people are overburdened with duties. Nonetheless, it has a value, not a moral but a social one, because what is useless for overfed John might have a high value for extremely unfed Adam. Nevertheless, universal benevo- 
lence considers the philanthropic act of John to be of little moral value, because it did not cause him almost any loss of happiness and even if it did, it was triggered by a mild surge of universal benevolence. For in terms of morality, an act is more valuable when more effort and selfdenial had to be put in it by the doer.

However, the vast majority of people satisfy their obligations only out of that extra at best. These are the obligations that follow from the second, third and fourth norms: for others, they deny themselves cakes that they had no room for anyway. If they carefully record in memory such stirrings of love for their neighbours, if in hindsight they view their trivial sacrifices in a certain magnification and if, what is more, they see the suffering of other people only at a very short distance, like the shortsighted, and even then they know how to discreetly pass over them, they feel morally just, or to put it differently, they feel that they satisfy all their moral obligations and demand from their community that they be given credit and respect. However, they will be denied that credit and respect by universally benevolent Peter, if he clearly sees how they have salved their conscience, which is as shallow as a rainwater puddle. He will call them by the name of Pharisees known from the Gospel. Despite not knowing the word yet, Plato wrote about such people with bitter irony.

The opposites of these pseudo-perfect people are those of uncomfortable conscience, who see clearly that they do not fully satisfy their moral obligations. They vigilantly and sensitively notice the suffering of other people and, realising its immense amount, find themselves helpless. Although they know, when they think dispassionately, that they are unable to help everybody who needs help, when they make concrete, direct contact with somebody else's suffering, they have the feeling that they have not done everything that their conscience dictates. They are not calmed either by the thought that by their work, which is their moral obligation, they make a certain contribution in kind to the overall sum of happiness. Such people will never feel morally perfect. They may come to terms, to an extent, with themselves if they take an active part in an 
organised or unorganised collective effort aimed at arranging the communal life so as to make the global sum of suffering continue to fall by itself, without any philanthropy. The very social system should, under the eyes of universal benevolence, be free from the causes of suffering and factors detracting from human joy.

Along the long frontline of struggle against suffering, people of good will keep taking positions voluntarily. This still does not make them morally perfect, but the thought and feeling of taking an active part in the great work of perfecting the human world, brings them relief from suffering on account of the suffering of other people and salves their conscience, to an extent.

In this case, too, universally benevolent Peter, but cautious due to experience, is circumspect in judging people. For he knows that the actions that were originally a means can easily become an end; to put it differently: an instrumental action easily becomes a consumerist action. Moreover, he is acutely aware of the tragically recurrent fact in the history of the human community that to improve a social system and to struggle against suffering, social power is necessary. In other words: it is necessary to have power to affect human relations by action. Power, being merely a means in the original intention, so easily provides so many benefits and self-satisfaction that it becomes a passionately desired end, which is often achieved through the mass suffering of other people. Furthermore, power is craved for itself, and not out of universal benevolence, by ambitious people whose poor emotional nature does not provide them with sufficiently diverse and strong joys and who, therefore, supplement the balance of their happiness by outpacing others and gaining a dominant position. Even the ambitious however, know that goodness wins the confidence of other people. Hence, they try, by word and action, to appear as if they have the happiness of all people at heart. 